Synthesis Alerts is a monthly feature to help readers of Synthesis keep abreast of new reagents, catalysts, ligands, chiral auxiliaries, and protecting groups which have appeared in the recent literature. Emphasis is placed on new developments but established reagents, catalysts etc are also covered if they are used in novel and useful reactions. In each abstract, a specific example of a transformation is given in a concise format designed to aid visual retrieval of information.

Synthesis Alerts is a personal selection by:

Fabrize Anizon, Robert Chow, Jennifer Delaney, Hassan Mamdani, Marcel de Puit and Sukhjinder Uppal, Department of Chemistry, Leeds University, Leeds, LS2 9JT, UK.

Georg Thieme Verlag does not accept responsibility for the accuracy, content, or selection of the data.

Synthesis 2001, No. 9, 2906 2001. Article Identifier: 1437-210X,E;2001,0,09,1427,1430,ftx,en;X00901SS.pdf.

(C) Georg Thieme Verlag Stuttgart · New York

ISSN 0039-7881
The journals regularly covered by the abstractors are:

Angewandte Chemie International Edition

Bulletin of the Chemical Society of Japan

Chemical Communications

Chemistry A European Journal

Chemistry Letters

Collection Czechoslovak Chemical Communications

European Journal of Organic Chemistry

Helvetica Chimica Acta

Heterocycles

Journal of the American Chemical Society

Journal of Organic Chemistry

Organic Letters

Organometallics

Perkin Transactions I

Synlett

Synthesis

Tetrahedron

Tetrahedron Asymmetry and Tetrahedron Letters

\begin{tabular}{l}
\hline Resin-bound Ruthenium Phosphine Complex \\
$\begin{array}{l}\text { The title reagent catalyses transfer } \\
\text { hydrogenation and hydrocarbon } \\
\text { oxidation reactions. }\end{array}$ \\
$\begin{array}{l}\text { Leadbeater, N. E. J. Org. Chem. 2001, } \\
66,2168 .\end{array}$
\end{tabular}

\begin{tabular}{l|l}
\hline Tris(triphenylsilyl)vanadate & Catalyst \\
\hline $\begin{array}{l}\text { The title reagent catalyses the aldol- } \\
\text { type addition of propargyl alcohols to } \\
\text { aldehydes. }\end{array}$ & \\
Trost, B. M.; Oi, S. J. Am. Chem. Soc. \\
2001, 123, 1230.
\end{tabular}

\title{
Zirconium Catalyst
}

Reagent A catalyses the one-pot synthesis of $\beta$-cyanohydrins from olefins.

Yamasaki, S.; Kanai, M.; Shibasaki, M. J. Am. Chem. Soc. 2001, 123, 1256.

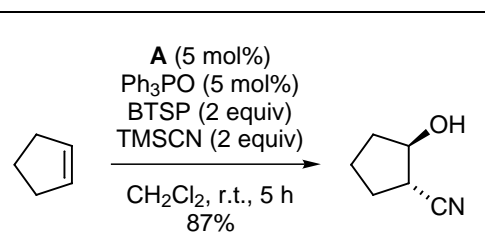

15 examples (yields 53-96\%). 
Reagent $A$ catalyses the reactions of acyl halides with halogenating agent $B$ to form $\alpha$-haloesters.

Wack, H.; Taggi, A. E.; Hafez, A. M.; Drury III, W. J.; Lectka, T. J. Am.

Chem. Soc. 2001, 123, 1531.
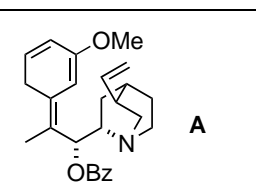

$$
\text { (c) }
$$
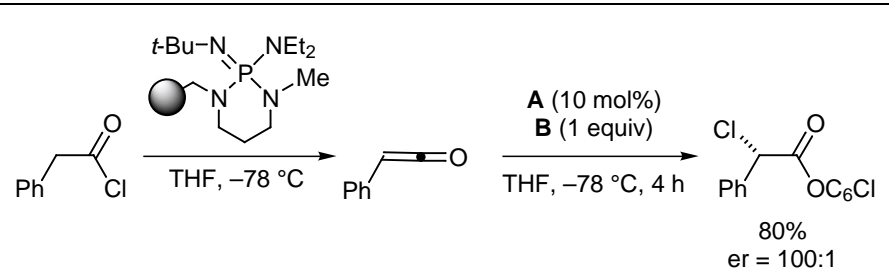

\section{$\mathrm{N}$-(9-Anthracenylmethyl)dihydrocinchonidinium Bromide}

Catalyst

The title reagent catalyses the enantioand diastereoselective Michael reaction of silyl enol ethers and chalcones.

Zhang, F.-Y.; Corey, E. J. Org. Lett. 2001, 3, 639.
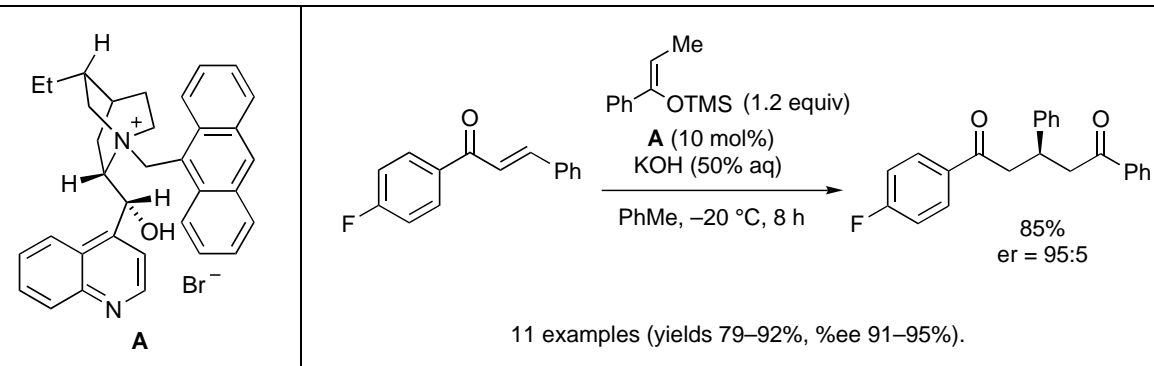

11 examples (yields $79-92 \%$, \%ee 91-95\%).

\begin{tabular}{l}
\hline Trimethyl(trifluoromethyl)silane \\
\hline $\begin{array}{l}\text { The title reagent is used for the } \\
\text { stereoselective nucleophilic } \\
\text { trifluoromethylation of } \mathrm{N} \text {-(tert- } \\
\text { butylsulfinyl)imines. }\end{array}$ \\
$\begin{array}{l}\text { Prakash, G. K. S.; Mandal, M.; Olah, G. } \\
\text { A. Angew. Chem. Int. Ed. 2001, 40, }\end{array}$ \\
589.
\end{tabular}

\section{Rhodium(II) Acetate Dimer}

The title reagent catalyses the $\mathrm{C}-\mathrm{H}$ insertion reaction for the oxidative conversion of carbamates to oxazolidinones.

Espino, C. G.; Du Bois, J. Angew. Chem. Int. Ed. 2001, 40, 598 .

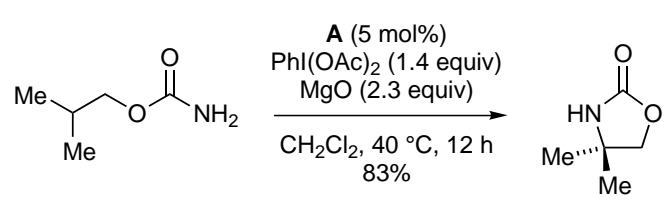

5 examples (yields $77-83 \%$ ).

\section{Tris(dibenzylideneacetone)dipalladium(0) Chloroform Adduct}

The title reagent catalyses the domino reaction of 4-methoxycarbonyloxy-2butyn-1-ols with phenols to form cyclic carbonates, with the recycling of carbon dioxide.

Yoshida, M.; Ihara, M. Angew. Chem. Int. Ed. 2001, 40, 616.

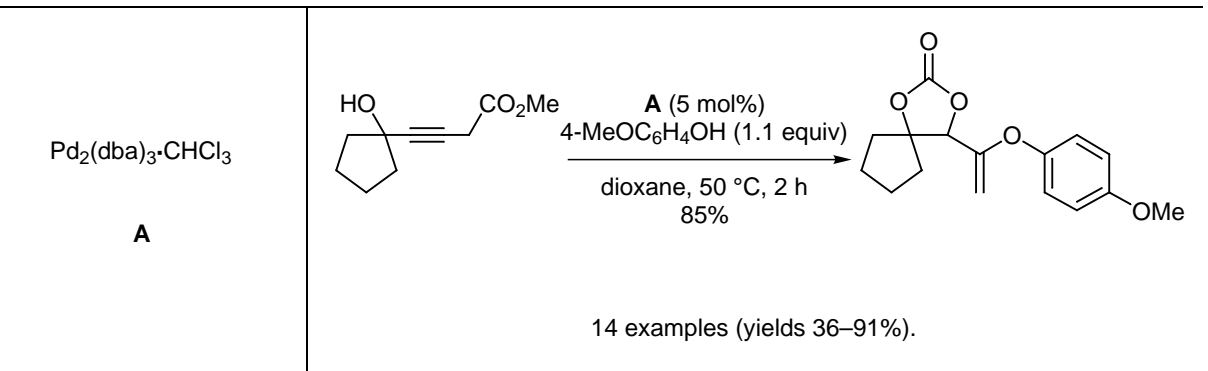




Heptacarbonyl(triphenylphosphine)dicobalt(0)
$\begin{aligned} & \text { The title reagent is a readily-prepared } \\ & \text { catalyst for the Pauson-Khand } \\ & \text { annulation. }\end{aligned}$
$\begin{aligned} & \text { Comely, A. C.; Gibson, S. E.; } \\ & \text { Stevenazzi, A.; Hales, N. J. } \\ & \text { Tetrahedron Lett. 2001, 42, 1183. }\end{aligned}$

N-Anthracenylmethyl Derivative of Cinchona Alkaloid
The title reagent is used for the
asymmetric phase-transfer mediated
epoxidation of $\alpha, \beta$-unsaturated
ketones.
Lygo, B.; To, D. C. M. Tetrahedron
Lett. 2001, 42, 1343.

The title tetraphosphine ligand is used in Pd-catalysed allylic substitutions.

Laurenti, D.; Feuerstein, M.; Pèpe, G.; Doucet, H.; Santelli, M. J. Org. Chem. 2001, 66, 1633.

8 examples (yields 58-100\%).

\section{Bis(sulfinyl)imidoamidine Ligand}

The title ligand is used for the asymmetric catalytic Diels-Alder reaction.

Owens, T. D.; Hollander, F. J.; Oliver, A. G.; Ellman, J. A. J. Am. Chem. Soc 2001, 123, 1539 .

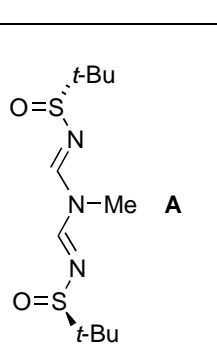

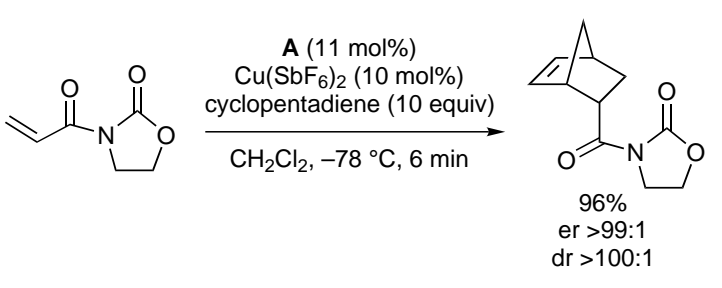

6 examples (yields $50-96 \%$, \%ee 32->98\%, \%de 90->98\%)

\section{Salen Ligand}

The title ligand is used in the yttriumcatalysed aldol-Tischenko reaction.

Mascarenhas, C. M.; Miller, S. P.; White, P. S.; Morken, J. P. Angew. Chem. Int. Ed. 2001, 40, 601. 
The title reagent is used in the Mitsunobu reaction of alcohols.

Charette, A. B.; Janes, M. K.; Boezio, A. A. J. Org. Chem. 2001, 66, 2178.

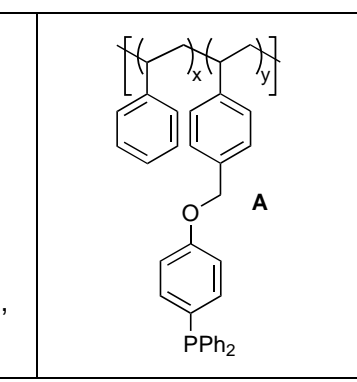

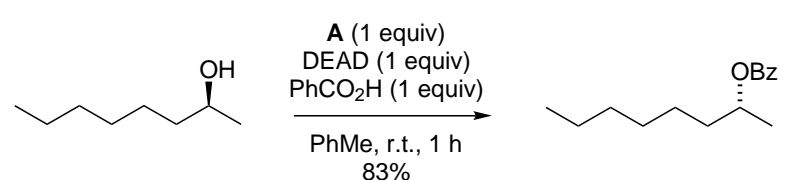

$83 \%$

5 examples (yields 71-88\%).

\section{Chiral Carbenium Ion}

Reagent

The title reagent is employed for enantioselective hydride abstraction.

Magdziak, D.; Pettus, L. H.; Pettus, T. R. R. Org. Lett. 2001, 3, 557.

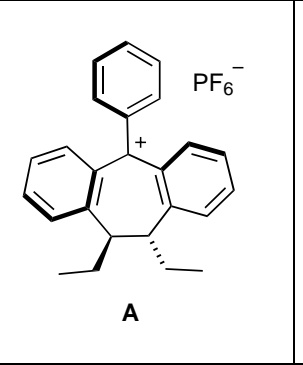

OC, $\mathrm{CO}$ OC-Fé

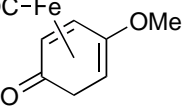

$71 \%$ er $=73: 27$

2 examples (yields $65-71 \%$, \%ee 43-53\%).

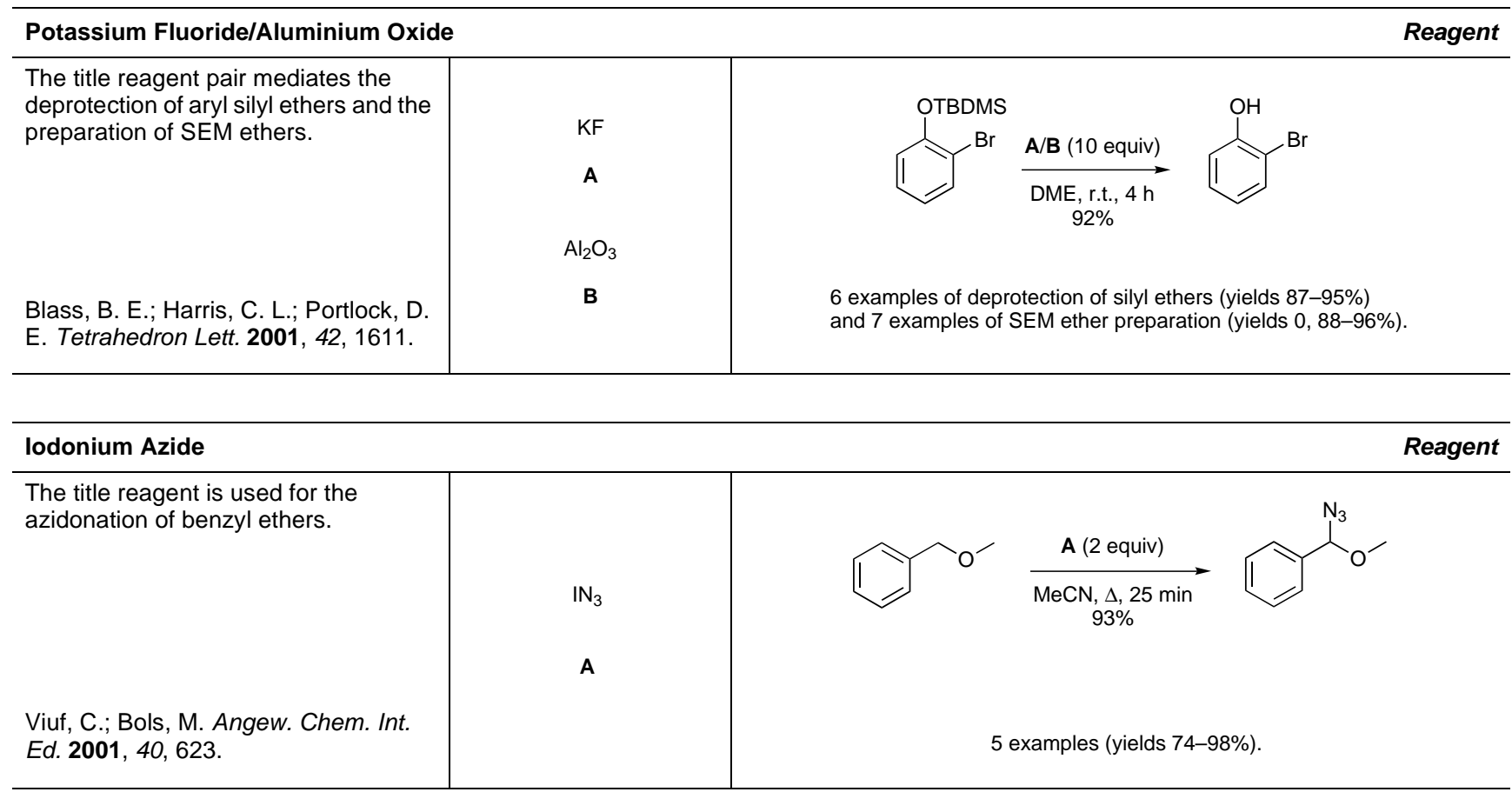

\section{$(R)-(+)-N, N$-Dimethyl-1-phenethylamine Derived Diselenide}

\begin{abstract}
The title reagent is used for the asymmetric methoxyselenenylation of alkyl vinyl ethers.
\end{abstract}

Uchiyama, M.; Satoh, S.; Ohta, A. Tetrahedron Lett. 2001, 42, 1559.

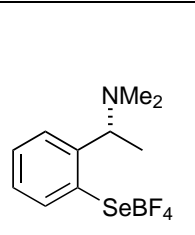

A 